\title{
Elemental Concentration and Sulfur Chemical Speciation in the Amazonian Plant Andira surinamensis Using Synchrotron Radiation Techniques (SR-XRF, XANES), RBS and WD-XRF
}

\author{
Joselaine C. Gonzalez, ${ }^{\circledR *} * a$ Grazieli Simões, ${ }^{a}$ Rafael B. Bernini, ${ }^{b}$ \\ Lúcia H. Coutinho, ${ }^{c}$ Fernanda C. Stedile, ${ }^{d}$ Cecilia V. Nunez, ${ }^{e}$ Flavio C. Vicentin ${ }^{f}$ \\ and Gerardo G. B. de Souza*a \\ ${ }^{a}$ Departamento de Físico-Química, Instituto de Química, Universidade Federal do Rio de Janeiro, \\ Av. Athos da Silveira Ramos, 149, Bloco A, $4^{\circ}$ andar, 21941-909 Rio de Janeiro-RJ, Brazil \\ ${ }^{b}$ Instituto Federal do Rio de Janeiro, Campus Duque de Caxias, Av. República do Paraguai, 120, \\ 25050-100 Duque de Caxias-RJ, Brazil \\ 'Instituto de Física, Universidade Federal do Rio de Janeiro, Av. Athos da Silveira Ramos, 149, \\ Bloco A, $3^{\circ}$ andar, 21941-929 Rio de Janeiro-RJ, Brazil \\ ${ }^{d}$ Instituto de Química, Universidade Federal do Rio Grande do Sul, Av. Bento Gonçalves, 9500, \\ 91509-900 Porto Alegre-RS, Brazil \\ eInstituto Nacional de Pesquisas da Amazônia, Coordenação de Tecnologia e Inovação, \\ Av. André Araújo, 2936, 69067-375 Manaus-AM, Brazil \\ ${ }^{f}$ Laboratório Nacional de Luz Síncrotron (LNLS), R. Giuseppe Máximo Scolfaro, 10000, \\ 13083-100 Campinas-SP, Brazil
}

\begin{abstract}
The inorganic composition of the bark and leaf of a plant from the Amazon rainforest, Andira surinamensis, was determined using two non-destructive, multi-element techniques: X-ray fluorescence (XRF) and Rutherford backscattering spectrometry (RBS). XRF measurements were made using both a conventional X-ray source and synchrotron radiation. It was observed that although magnesium, aluminum, silicon, phosphorus, sulfur, chlorine, and potassium are present in higher concentrations in the leaf, calcium is about three times more concentrated in the bark. Manganese, iron, copper, zinc, strontium and barium were also detected, with barium showing a concentration above the minimum toxicity level for plants. Chemical speciation of sulfur, performed using the X-ray absorption near edge structure (XANES) technique, showed that sulfur is present in several oxidation states, with a much larger contribution from the inorganic sulfate in the leaves. The article evidences that the combined use of synchrotron radiation and non-destructive multielement techniques allows for an efficient and accurate determination of the inorganic composition and chemical speciation in plants.
\end{abstract}

Keywords: WD-XRF, SR-XRF, RBS, XANES, Andira surinamensis

\section{Introduction}

Although plants are composed mainly (around 98\%) of low atomic number elements (carbon, hydrogen, nitrogen, and oxygen), metals and trace elements, which are obtained primarily from the soil through the roots, play a decisive role in the plant metabolism. ${ }^{1,2}$

*e-mail: joselainecaceres@gmail.com; gerson@iq.ufrj.br
The mineral nutrient and trace elements content (the ionome) present an intimate connection with plant's physiology. ${ }^{3,4}$ With the exception of carbon and oxygen, the majority of the elements that make up a plant are obtained from the soil through complex processes related to plant-environment interactions. ${ }^{5}$ Information concerning the accumulation of metals and trace elements in different parts of the plants is of primary importance in the study of metal homeostasis, that is, the mechanisms related to 
the uptake, transport and storage of metals in plants. ${ }^{6}$ The development of fast and non-destructive methodologies dedicated to the determination of the elemental composition of plants and parts of plants has become consequently of paramount importance.

As part of a systematic study of the metal and trace element composition of plants using advanced techniques, the composition of the bark and leaf of a plant from the Amazon rainforest, Andira surinamensis, has been determined using two multi-element techniques: X-ray fluorescence (XRF) and Rutherford backscattering spectrometry (RBS). XRF measurements were made using both a conventional X-ray source (wavelength dispersive (WD)-XRF) and a synchrotron radiation source (synchrotron radiation (SR)-XRF).

In addition to the qualitative and quantitative elemental determination using XRF and RBS, the chemical speciation of sulfur has been performed using the X-ray absorption near edge structure (XANES) technique. Sulfur is one essential nutrient, usually present in plants in several oxidation forms. ${ }^{7}$ It is usually obtained from the soil in a sulfate form and then subjected to a complex reaction manifold. Sulfur is also an essential participant in the biosynthesis of amino acids (methionine and cysteine), peptides such as glutathione, lipids and vitamins. Information concerning the chemical ambiance of sulfur in different parts of a plant may consequently be extremely useful to the study of the plant metabolism. The role of elemental sulfur as an antifungal substance in plant defense has been the focus of several studies. ${ }^{89}$ The use of XANES for this characterization is quite appropriate as this technique does not require the use of extraction and other chemical procedures which could otherwise induce changes in the prevailing chemical ambiance. It should also be pointed out that the application of nuclear magnetic resonance (NMR) spectroscopy to this element is difficult because the predominant sulfur isotope ${ }^{32} \mathrm{~S}$ lacks nuclear spin, while the ${ }^{33} \mathrm{~S}$ isotope provides weak and broad signals.

Andira surinamensis, the plant to which we address our attention in the present paper, is widely found in the Amazon rainforest region. It is frequently used in traditional medicine, such as in the treatment of a skin disease, pityriasis versicolor, known as "pano branco" in the north of Brazil. It is also well known that sulfur is commonly used in dermatology for the treatment of skin diseases such as pityriasis versicolor, caused by fungus. The widespread use of this plant by people from the Amazonian region and the paucity of studies related to its inorganic composition have also motivated this research. A careful analysis of the metals and trace elements existent in useful parts of the plants may be of considerable importance towards the screening of potentially dangerous components. It is our hope that the sulfur chemical speciation and determination of the trace elements content in the bark and in the leaves of Andira suraminensis might also be useful towards the use of this plant in skin diseases treatment.

\section{Experimental}

$\mathrm{XRF}$ is a non-destructive and multi-element technique, which has been widely used towards the qualitative and quantitative determination of metals in vegetal materials. ${ }^{1,10,11}$ In WD-XRF, following irradiation of the sample using a standard X-ray source, the characteristic radiation emitted by the sample is separated into wavelengths using a diffraction device. In SR-XRF the energy of the incident photon beam can be tuned as to take full advantage of the energy dependence of the photoexcitation cross section thus increasing the sensitivity of the method. ${ }^{11}$ This is for instance of great relevance for the study of metal and trace elements distribution in plants with 2D and 3D images techniques. ${ }^{12}$ In the present research, measurements were performed at $2500 \mathrm{eV}$ (a few $\mathrm{eV}$ above the sulfur K-edge) and $4200 \mathrm{eV}$ (a few eV above the calcium K-edge) to enable the observation and analysis of low atomic number elements $(Z=20$ and below) with very good resolution and excellent signal-to-noise ratio. RBS is a multi-element technique based on the counting and energy determination of backscattered ions $\left(\mathrm{He}^{+}\right)$ of $2 \mathrm{MeV}$ upon a solid sample. This technique is more sensitive to high atomic number elements but also allows the determination of carbon and oxygen, which are hardly detected by conventional XRF. Experimental details for the $\mathrm{XRF}$ and RBS experiments are presented below.

\section{WD-XRF}

WD-XRF measurements were performed using a $1 \mathrm{~kW}$, wavelength dispersive, commercial spectrometer (Bruker, model S8 Tiger). The spectrometer features a rhodium $(\mathrm{Rh})$ anode $\mathrm{X}$-ray tube with a beryllium $(\mathrm{Be})$ window, refrigerated with an internal water-cooling system. Spectra were recorded from 0.5 to $50 \mathrm{keV}$ photon energy range, enabling the detection of elements from fluorine to uranium. Three analyzing crystals are used in order to cover the entire spectrum: XS-55 from fluorine to magnesium, pentaerythritol (PET) from aluminum to chlorine, and LiF200 from potassium to uranium. ${ }^{13}$ In addition, two detectors perform the counting of the fluorescence yield: a gas proportional counter for elements of low atomic number (from fluorine to vanadium) and a scintillation counter for elements of high atomic number (from chromium to 
uranium). Quantitative chemical analysis was based on the use of a standard-less application, QuantExpress (Bruker AXS). Standard-less results are obtained from fundamental parameters calculations (incident beam intensity, detector efficiency, fluorescence yield, etc. $)^{14,15}$ without the need for calibration curves. QuantExpress has already provided good results for the fast screening and determination of the inorganic composition of plants and related materials, with a bias of typically $<5 \%$ for elements with concentrations above $0.1 \%$, and a $20 \%$ bias when concentrations are closer to the limit of detection (LOD) of a given element. ${ }^{10}$

Samples were milled to a fine powder and attached to a sample-holder assembled with a $4 \mu \mathrm{m}$ thin film (3525 Ultralene-SPEX®SamplePrep), supported in a low $\mathrm{Z}$ material. Measurements were performed under a helium atmosphere at reduced pressure using a $34 \mathrm{~mm}$ mask to maximize the irradiated area.

Data acquisition was done using the software routine "Best Detection" (17 min measurement routine) available in QuantExpress and detailed elsewhere. ${ }^{10}$ Because quantification requires the use of an organic matrix formula, we used cellulose, which has been demonstrated to be a good matrix formula for plants. ${ }^{10}$ Measurements were made in triplicate and the standard deviation of the mean has been reported. LODs were calculated by the spectrometer software and limits of quantification (LOQ) were obtained from LODs applying a factor of $10 / 3,{ }^{16}$ see Supplementary Information (SI) section, Table S1.

Careful validation of the WD-XRF methodology was performed using the certified reference material SRM 1570a (spinach leaves) from the National Institute of Standards and Technology (NIST) ${ }^{17}$ (see Table S2, SI section), measured in the same conditions as the samples. The estimated accuracy of the results was better than $5 \%$ in most cases, except for those elements present in very low concentrations (less than $0.01 \%$ in mass) and of low $\mathrm{Z}$. This is in line with previously reported validation results obtained from the use of a similar spectrometer. ${ }^{10}$

\section{SR-XRF}

SR-XRF measurements were performed using the photon beam provided by the soft X-ray spectroscopy (SXS) beamline of the Brazilian Synchrotron Laboratory (LNLS). The SXS beamline covers the energy range from 1000 up to $5500 \mathrm{eV}$, and has been previously described in detail elsewhere. ${ }^{18}$ For the SR-XRF measurements, the samples were milled to a fine powder, homogenized and finely spread onto a conductive double-sided carbon tape mounted on a sample holder. The excess of powder was removed in order to avoid contamination of the chamber and additional self-absorption issues. SR-XRF spectra were acquired at two different incident photon energies, 2500 and $4200 \mathrm{eV}$, under high vacuum conditions. This procedure allowed for the observation of low atomic number elements $(\mathrm{Z}=20$ and below) with much better resolution and signal-to-noise ratio as compared to the WD-XRF measurements. Detection was performed using a silicon drift detector (SuperFast SDD, AMPTEK, Model XR-100 SDD).

\section{RBS}

RBS analysis was performed using the 3 MV Tandetron HVEE ion accelerator located at the Ion Implantation Laboratory at the Federal University of Rio Grande do Sul (UFRGS). ${ }^{19}$ It uses a $2 \mathrm{MeV}$ incident $\mathrm{He}^{+}$beam perpendicular to the sample surface and detects the backscattered particles at $165^{\circ}$ from the direction of the beam, using diode type detectors obtained by ion implantation of dopants. Calculated elements relative concentrations from spectra present an accuracy of about $10 \%,{ }^{20}$ and were obtained using ratios of the elements signal heights, since the relative amount of $\mathrm{H}$ is considerable in the samples and RBS cannot detect it. ${ }^{21}$ Samples were milled into a fine powder and then pressed $(8 \mathrm{t}$ ) into a $10 \mathrm{~mm}$ diameter pellet. During analysis, the base pressure in the chamber was kept in the $10^{-6}$ mbar pressure range.

\section{XANES}

In XANES, the core electron excitation of a selected atom is observed by scanning the incident synchrotron photon energy around the selected absorption edge energy, resulting in a photoabsorption spectrum very sensitive to the atom chemical environment. Speciation of the sulfur atom using synchrotron radiation has been the focus of several XANES studies. ${ }^{22-33}$ Using the XANES technique, it is possible to perform the sulfur chemical speciation in different plant tissues through the identification and quantification of the sulfur functional groups. ${ }^{34-43}$

XANES measurements were performed at the SXS beamline of the LNLS. ${ }^{18}$ Spectra acquisition were made either in the total electron yield (TEY) or in the fluorescence yield (FL) detection modes. In the TEY mode an electrometer detector (Keithley, Model 6514) was used, whereas in the fluorescence mode a silicon drift detector (SuperFast SDD, AMPTEK, Model XR-100 SDD) was used. The flux density in the beamline is $4 \times 10^{11} \mathrm{ph} \mathrm{s}^{-1}$ at $3 \mathrm{keV}$. The incident photon energy was selected by a $\mathrm{Si}(111)$ double-crystal monochromator with an energy bandwidth of $0.5 \mathrm{eV}$. SXS energy calibration is routinely performed measuring the XANES spectrum of an ultrapure 
molybdenum foil in the TEY mode and adjusting the zero of the second derivative of the spectra to $2520 \mathrm{eV}^{44}$

XANES spectra were obtained around the sulfur $\mathrm{K}$-edge for the Andira surinamensis samples as well as for a collection of pure components taken as standards (SI section, Figure S1). The choice of the standards was based on their sulfur functional group: disulfide $-\mathrm{C}-\mathrm{S}-\mathrm{S}-\mathrm{C}-$ (cystine and oxidized glutathione), thiol $-\mathrm{S}-\mathrm{H}$ (cysteine and reduced glutathione), thioether $-\mathrm{C}-\mathrm{S}-\mathrm{C}-(\mathrm{DL}-\mathrm{methionine})$, sulfoxide (dimethyl sulfoxide), sulfone (L-methionine sulfone), sulfonic acid (cysteic acid), organic and inorganic sulfates (chondroitin sulfate and zinc sulfate). The spectrum of elemental sulfur $\left({ }^{\circ} \mathrm{S}_{8}\right)$ was taken from the ID21 sulfur XANES spectra database European Synchrotron Radiation Facility (ESRF). ${ }^{45}$ Solid high-purity standards were measured in the TEY detection mode, thus avoiding selfabsorption issues. The dimethyl sulfoxide (DMSO; Vetec Química Fina LTDA, Rio de Janeiro, Brazil) spectrum was measured in the fluorescence yield mode, using an aqueous solution of $4 \mathrm{mg} \mathrm{g}^{-1}$ of sulfur, in a special sample holder designed for liquids, constituted by a Teflon® holder and covered with a $4 \mu \mathrm{m}$ X-ray film (3525 Ultralene-SPEX ${ }^{\circledR}$ SamplePrep). Standard compounds were purchased from Sigma-Aldrich (St Louis, MO, USA) and measured with no further preparation other than milling. The spectrum of one of the standards, cysteine, was repeatedly measured, following the calibration and the acquisition of spectra for the samples and other model compounds, in order to verify the stability and reproducibility of the experimental methodology. We have previously observed that in similar experimental conditions (beam energy and intensity, spectral acquisition parameters) the cysteine sulfur K-edge spectrum remains basically unchanged even after repeated spectra acquisition using the same sample. ${ }^{46}$ In the cysteine spectrum, the white line was observed at $2471.3 \mathrm{eV}$, whereas its second derivative determination of $\mathrm{E}_{0}$ was observed at $2470.66 \mathrm{eV}$. Spectra were obtained in a large energy domain, 2400 to $2600 \mathrm{eV}$, in order to allow for an accurate step height normalization. An energy step of $2 \mathrm{eV}$ was used in the 2400 to 2440 and 2560 to $2600 \mathrm{eV}$ energy intervals, while steps of $1 \mathrm{eV}$ were used in the 2440 to 2465 and 2500 to $2560 \mathrm{eV}$ intervals. High resolution data were obtained in the 2465 to $2500 \mathrm{eV}$ energy interval using a $0.2 \mathrm{eV}$ energy step. Spectra were normalized to the current of the incident photon beam, $\mathrm{I}_{0}$, measured using a gold mesh placed before the sample. Step height normalization was performed using the standard procedure available in the ATHENA software package.$^{47}$ Spectra of the parts of the plant were measured in the fluorescence mode. The relatively low concentration of sulfur in each sample prevented the occurrence of self-absorption effects.

\section{Plant material}

Plant material was collected in Volta Grande do Xingu, Altamira, state of Pará, Brazil, on August 25, 2009. The material was separated into its parts, dried in a drying chamber at $50{ }^{\circ} \mathrm{C}$ and milled, preserving their biologicals properties. A voucher was deposited in the Herbarium of the Federal Institute of the Amazon (IFAM) under number 10611.

\section{Results and Discussion}

\section{WD-XRF}

The absolute concentration of the inorganic components found in the bark and leaf samples has been determined through WD-XRF and the results and corresponding standard deviation are presented in Table 1 (spectra in SI section, Figures S2 and S3).

Table 1. Inorganic components concentration of the Andira surinamensis samples determined by WD-XRF

\begin{tabular}{lcc}
\hline & \multicolumn{2}{c}{ Measured concentration $/\left(\mu \mathrm{g} \mathrm{g}^{-1}\right)$} \\
\cline { 2 - 3 } $\mathrm{Mg}$ & Bark & Leaf \\
$\mathrm{Al}$ & $1250 \pm 60$ & $3840 \pm 80$ \\
$\mathrm{Si}$ & $150 \pm 20$ & $210 \pm 40$ \\
$\mathrm{P}$ & $300 \pm 40$ & $2130 \pm 120$ \\
$\mathrm{~S}$ & $540 \pm 10$ & $1060 \pm 80$ \\
$\mathrm{Cl}$ & $290 \pm 20$ & $1480 \pm 60$ \\
$\mathrm{~K}$ & $120 \pm 11$ & $720 \pm 10$ \\
$\mathrm{Ca}$ & $1230 \pm 20$ & $10170 \pm 160$ \\
$\mathrm{Mn}$ & $15750 \pm 560$ & $4600 \pm 40$ \\
$\mathrm{Fe}$ & - & $33 \pm 5$ \\
$\mathrm{Cu}$ & $48 \pm 9$ & $200 \pm 10$ \\
$\mathrm{Zn}$ & - & $43 \pm 4$ \\
$\mathrm{Sr}$ & $310 \pm 10$ & $34 \pm 1$ \\
$\mathrm{Ba}$ & $890 \pm 60$ & $120 \pm 10$ \\
\hline$: \mathrm{n}$ & $450 \pm 50$ \\
\hline & &
\end{tabular}

-: not detected or below the limit of quantification.

From Table 1 we observe that except for calcium, all the major elements (magnesium, silicon, phosphorus, sulfur, chlorine and potassium) are present in higher concentrations in the leaf as compared to the bark. Manganese, iron, copper, and zinc were also detected, albeit in lower concentrations, as well as the high atomic number alkaline earths strontium and barium. The presence of strontium and barium in the leaf and in the bark of Andira surinamensis is particularly interesting. To our 
knowledge, there is no previous report of the accumulation of these metals in these concentrations in this plant. As shown in Table 1, barium and strontium have been detected in concentrations as high as $890 \mu \mathrm{g} \mathrm{g}^{-1}$. The barium uptake by plants has been already discussed by other research groups who pointed out that barium has a potential to follow the potassium and calcium geochemistry, becoming available to plants. Its uptake can be considerable if present in the soil. ${ }^{48,49} \mathrm{We}$ remark that barium and strontium are observed with higher concentrations in the bark, and the same behavior is observed for calcium. Considering that barium may already be considered toxic in concentrations of about $500 \mu \mathrm{g} \mathrm{g}^{-1},{ }^{10,51}$ we suggest that Andira suraminensis should have a yet unknown strategy to accumulate barium at levels above toxicity without compromising its metabolisms and development. It is known that some plants may adapt to soils presenting a significant concentration of toxic metals. ${ }^{52}$ Several reports of barium concentration in Brazilian soils indicate that a concentration of 4 to $446 \mu \mathrm{g} \mathrm{g}^{-1}$ is expected in soils of forests from the north and northeast regions of Brazil. ${ }^{53,54}$ Although present in a lower concentration $\left(310 \mu \mathrm{g} \mathrm{g}^{-1}\right)$ when compared to barium, the observed presence of strontium may also deserve future investigation. It has been observed, for instance, that in some members of the Leguminosae, elements such as calcium, strontium and barium may be found as sulfate crystals or oxalate crystals, in a plant strategy to avoid toxicity. ${ }^{55}$ Sulfur speciation (see XANES results) shows that in the bark (where strontium and barium are observed in larger concentrations) the low amount of sulfate eliminates the hypothesis of sulfate crystals formation. It is also important to remark that, from folk knowledge, members of Andira genus are used in several other applications of traditional medicine,

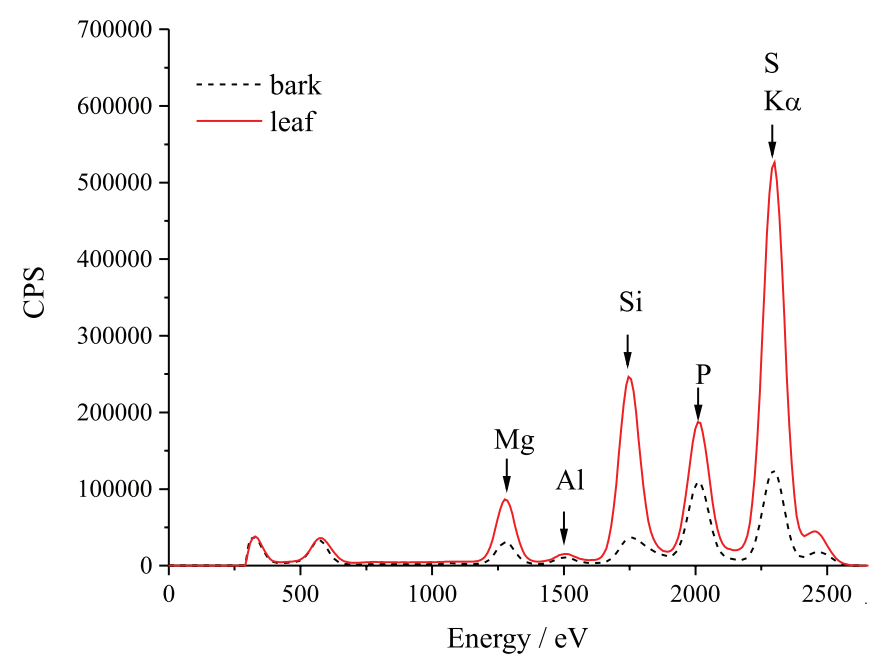

and intoxication has been reported from its use, raising questions to whether its toxicity may be related or not to the heavy alkaline earths detected.

\section{SR-XRF}

In the SR-XRF measurements, the atomic ratios of the elements from magnesium to calcium were determined relative to sulfur. The ratios were determined based on the use of fundamental parameters, without the need of standard measurements. ${ }^{56,57}$

SR-XRF spectra of Andira surinamensis bark and leaf obtained at 2500 and $4200 \mathrm{eV}$ incident photon energies are shown in Figure 1. At these two incident photon energies, the inorganic components observed in higher concentrations are magnesium, aluminum, silicon, phosphorus, sulfur, chlorine, potassium, and calcium. The atomic ratios of these elements $\left(\frac{X}{S}\right)$ with respect to the sulfur atom are presented in Table 2 along with their combined standard uncertainty $\mathrm{u}$ (calculated using the law of propagation of uncertainty). ${ }^{58}$ The normalized errors were obtained using the expression $\mathrm{En}=\frac{\left(\frac{\mathrm{X}}{\mathrm{S}}\right)_{\mathrm{SR}-\mathrm{XRF}}-\left(\frac{\mathrm{X}}{\mathrm{S}}\right)_{\mathrm{WD}-\mathrm{XRF}}}{2 \sqrt{\left(\mathrm{u}_{\mathrm{SR}-\mathrm{XRF}}\right)^{2}+\left(\mathrm{u}_{\mathrm{WD}-\mathrm{XRF}}\right)^{2}}}$. All data have been corrected with respect to the photoabsorption cross section and the fluorescence yield. Corrections due to beam attenuation were applied to the low energy incident beam and to the low energy fluorescent lines, ${ }^{56,57}$ using the appropriate attenuation coefficients. Attenuation coefficients for the incident and fluorescent beams were obtained from the NIST XCOM database, ${ }^{59}$ calculated for the matrix (cellulose) at the energy of the incident beam and elements $\mathrm{K}-\mathrm{L}_{2,3}$ lines. Due to the low thickness of the

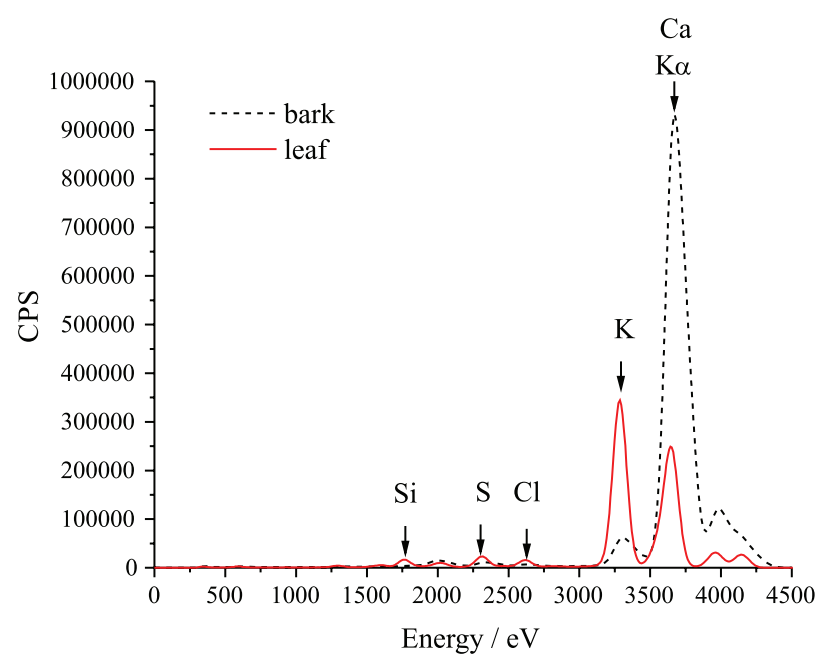

Figure 1. SR-XRF spectra of Andira surinamensis bark (black dashed line) and leaf (red solid line) measured at 2500 (left) and $4200 \mathrm{eV}$ (right) incident energies. 
Table 2. Comparative results of Andira surinamensis samples determined by WD-XRF and SR-XRF

\begin{tabular}{|c|c|c|c|c|c|c|}
\hline \multirow{3}{*}{$X$} & \multicolumn{6}{|c|}{$\mathrm{X} / \mathrm{S}$ atomic ratio } \\
\hline & \multicolumn{2}{|c|}{ SR-XRF } & \multicolumn{2}{|c|}{ WD-XRF } & \multicolumn{2}{|c|}{$|\mathrm{En}|$} \\
\hline & Bark & Leaf & Bark & Leaf & Bark & Leaf \\
\hline $\mathrm{Mg}$ & $6.03 \pm 0.56$ & $3.77 \pm 0.35$ & $5.57 \pm 0.45$ & $3.45 \pm 0.23$ & 0.32 & 0.38 \\
\hline $\mathrm{Al}$ & $0.79 \pm 0.07$ & $0.21 \pm 0.02$ & $0.66 \pm 0.07$ & $0.16 \pm 0.03$ & 0.68 & 0.78 \\
\hline $\mathrm{Si}$ & $1.13 \pm 0.10$ & $1.57 \pm 0.15$ & $1.14 \pm 0.09$ & $1.66 \pm 0.11$ & 0.04 & 0.25 \\
\hline $\mathrm{P}$ & $1.54 \pm 0.14$ & $0.67 \pm 0.06$ & $1.73 \pm 0.10$ & $0.75 \pm 0.05$ & 0.54 & 0.48 \\
\hline S & 1.00 & 1.00 & 1.00 & 1.00 & - & - \\
\hline $\mathrm{Cl}$ & $0.44 \pm 0.05$ & $0.49 \pm 0.05$ & $0.30 \pm 0.04$ & $0.43 \pm 0.02$ & 0.99 & 0.60 \\
\hline $\mathrm{K}$ & $2.57 \pm 0.25$ & $5.74 \pm 0.53$ & $3.28 \pm 0.29$ & $5.69 \pm 0.30$ & 0.92 & 0.04 \\
\hline $\mathrm{Ca}$ & $30.70 \pm 3.0$ & $3.06 \pm 0.28$ & $42.0 \pm 4.0$ & $2.51 \pm 0.14$ & 1.13 & 0.87 \\
\hline
\end{tabular}

SR-XRF: synchrotron radiation based X-ray fluorescence; WD-XRF: wavelength dispersive X-ray fluorescence spectrometry; |En|: normalized error.

sample, corrections due to attenuation were not applied to the higher energies (both incident and fluorescent). All elements detected in the SR-XRF measurements were also observed in the WD-XRF measurements (refer to Table 2). The SR-XRF and WD-XRF atomic ratios were compared using the normalized errors, that is, considering the difference in the ratios obtained through SR-XRF and WD-XRF relative to the combined uncertainty of the reported values. The ratios are considered to be statistically equivalent if $|\mathrm{En}|<1$ for an estimated $95 \%$ of confidence. We observed that $|\mathrm{En}|<1$ in all cases except for calcium in the bark sample measured at $4200 \mathrm{eV}$. This may happen due to the specific conditions of this sample in which calcium has a much larger concentration as compared to sulfur (Table 1). Small errors in the determination of the sulfur values will consequently have a large impact in the ratio's estimation.

\section{RBS}

RBS results were also determined without using standard measurements. RBS spectra of the Andira surinamensis bark and leaf are presented in Figures 2 and 3. The main contributions come from carbon, oxygen, calcium and barium. Potassium, strontium and zinc are also observed in both samples. Manganese, aluminum, silicon, phosphorus, iron, and sulfur probably contribute to the spectra but are not clearly distinguishable. Barium and strontium have been detected by both techniques, RBS and WD-XRF. In each RBS spectrum the vertical arrows indicate the outermost position of the corresponding elements in the sample spectra.

A noticed disadvantage of RBS when compared to the other techniques is the lower resolution which prevents the differentiation between elements with similar atomic mass (potassium / calcium; aluminum / silicon; etc.) especially

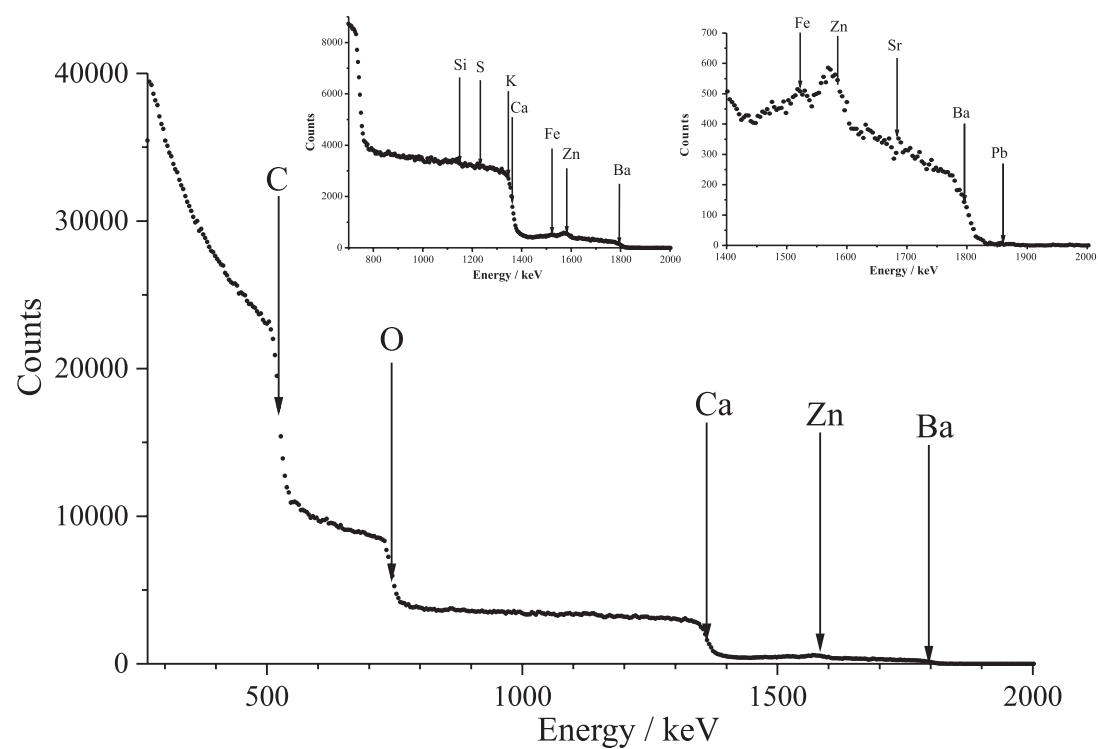

Figure 2. RBS spectra of the Andira surinamensis bark sample. Details of element signals not visible in the main spectrum are presented in the insets. In the insets, the spectrum on the left highlights signals from medium atomic numbers, while the spectrum on the right highlights signals from higher atomic numbers. 


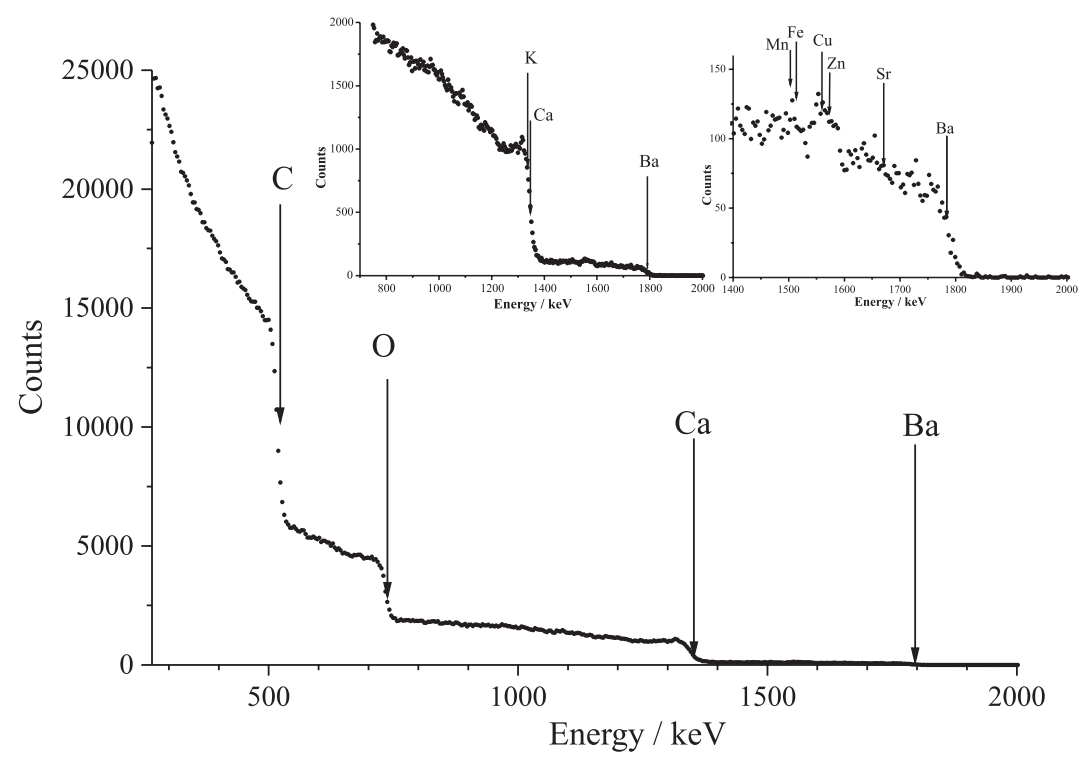

Figure 3. RBS spectra of Andira surinamensis leaf. Details of element signals not visible in the main spectrum are presented in the insets. In the insets, the spectrum on the left highlights signals from medium atomic numbers, while the spectrum on the right highlights signals from higher atomic numbers.

when the lighter element is present in lower concentration. This becomes more evident for heavier elements due to the non-linearity of the mass scale. ${ }^{60,61}$ In this research, for instance, it was not possible to separate the contributions from calcium and potassium. The atomic ratio of carbon, oxygen and barium were determined against the sum of the contributions of calcium and potassium with an accuracy of about $10 \% .{ }^{20}$ These results are presented in Table 3.

Table 3. Atomic ratios relative to (calcium + potassium) of Andira surinamensis determined by RBS

\begin{tabular}{lcc}
\hline & Bark & Leaf \\
\hline $\mathrm{C} /(\mathrm{Ca}+\mathrm{K})$ & 65 & 130 \\
$\mathrm{O} /(\mathrm{Ca}+\mathrm{K})$ & 12 & 20 \\
$\mathrm{Ba} /(\mathrm{Ca}+\mathrm{K})$ & 0.01 & 0.01 \\
\hline
\end{tabular}

The $\mathrm{Ba} /(\mathrm{Ca}+\mathrm{K})$ stoichiometric ratio can be compared with the relative quantifications obtained using the WD-XRF technique. By converting mass concentration to atomic concentration, the $\mathrm{Ba} /(\mathrm{Ca}+\mathrm{K})$ results of WD-XRF are $0.015 \pm 0.002$ and $0.010 \pm 0.001$ respectively for the bark and leaf, evidencing a good agreement with the RBS result. As carbon and oxygen were detected only by RBS, it is not possible to establish a comparison with the two other techniques. From the data on Table 3, it can be observed that the relative amounts of carbon and oxygen are larger in the leaf.

\section{XANES}

XANES spectra of the Andira surinamensis bark and leaf have been measured around the sulfur K-edge and the results are shown in Figures 4 and 5, respectively. In both spectra it is possible to identify three major features in the $2460-2485 \mathrm{eV}$ photon energy range. As already mentioned, from the XANES spectrum it is possible to obtain information on the chemical functional groups to which a given atom is attached. In the sulfur K-edge spectra of plants samples, the first spectral feature, observed around $2471 \mathrm{eV}$, is usually associated with organic sulfur, ${ }^{38,62}$ species containing thiol, disulfide and thioether groups. These groups are present in amino acids (cysteine, cystine and methionine) and peptides like oxidized glutathione and reduced glutathione (GSH), which play an important role in the defense against oxidative stress. The second feature, observed around $2475 \mathrm{eV}$, is usually associated with intermediate oxidized species such as sulfoxide groups. ${ }^{38,62}$ The last feature, observed around $2480 \mathrm{eV}$, is generally associated with highly oxidized species such as sulfate, sulfonate or sulfone groups. ${ }^{38,62}$ In order to identify which functional groups contributed to each of the three observed features, the sulfur K-edge spectra of a set of standard compounds (cysteine, cystine, methionine, oxidized glutathione, reduced glutathione, dimethyl sulfoxide, L-methionine sulfone, cysteic acid, chondroitin sulfate and zinc sulfate) were measured under the same experimental conditions. The spectra of the standards were then used in a best-fit analysis of the spectral features observed in the Andira surinamensis spectra. This analysis was performed using the ATHENA package, ${ }^{47}$ as well as other spectra analysis techniques like derivative techniques, ${ }^{63}$ and principal component analysis. ${ }^{34,35}$ Linear combination fitting (LCF) results include only the standards that best 


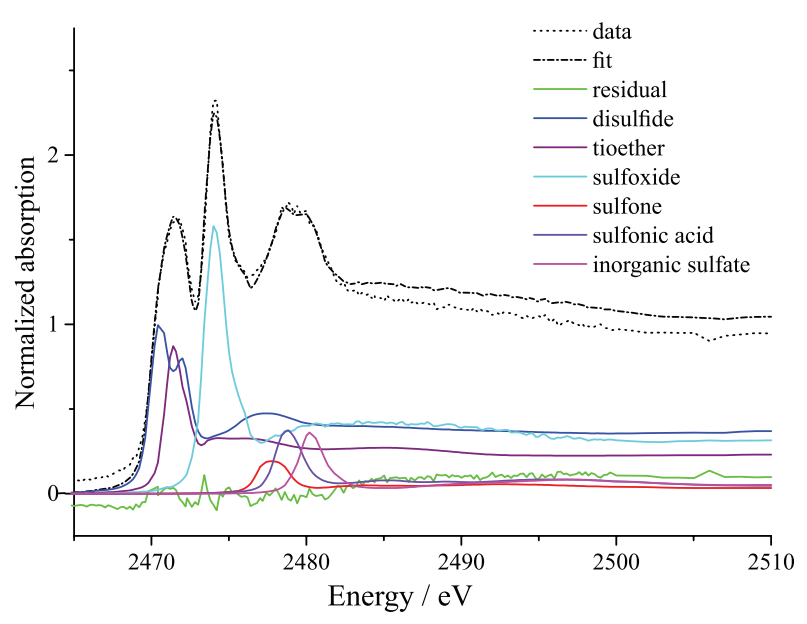

Figure 4. XANES spectra of Andira surinamensis bark. Linear combination fitting and components are plotted together with experimental data.

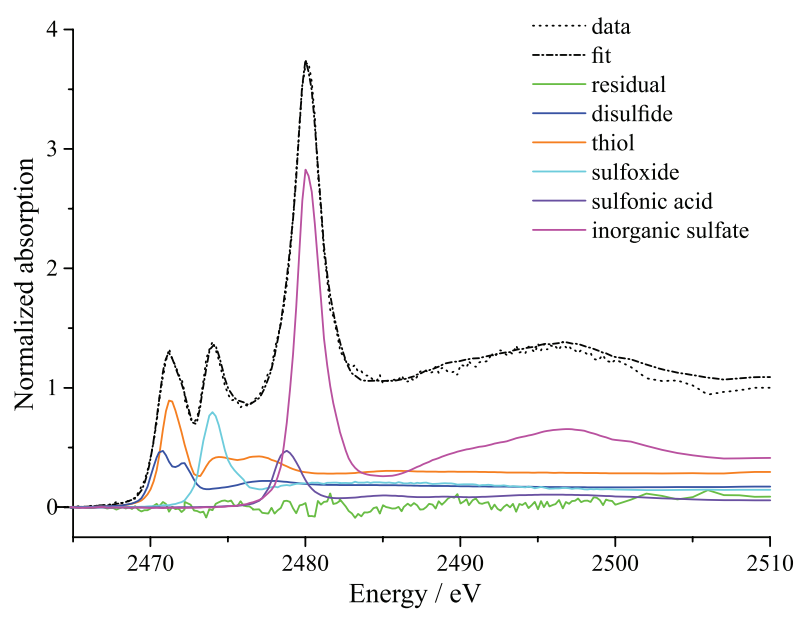

Figure 5. XANES spectra of Andira surinamensis leaf. Linear combination fitting and components are plotted together with experimental data.

represent the samples. The percentage contribution of the functional groups which contribute to the bark and leaf spectra was obtained adopting an LCF procedure and the result is presented in Table 4 along with the fit uncertainty (corresponding to 1 standard deviation) as reported by ATHENA. No feature related to elemental sulfur position has been observed.

In the bark spectrum, the complex shape of the feature observed around $2480 \mathrm{eV}$ is explained from the contribution of at least three highly oxidized groups: sulfone, sulfonic acid and inorganic sulfate. In the leaf spectrum, the analog feature is sharp and intense, revealing the existence of a dominant sulfur species (inorganic sulfate). The intermediate feature, on the other hand, is sharper and more intense in the bark than in the leaf, indicating the predominance of one intermediate oxidized species in the bark (sulfoxide). In the spectra feature observed around $2471 \mathrm{eV}$, the contributions from oxidized glutathione and from reduced glutathione are observed in the leaf whereas in the bark the observed contributions originate from oxidized glutathione and methionine.

From the WD-XRF (Table 1) and SR-XRF (Figure 1) analysis, we may conclude that the sulfur concentration is about five times larger in the leaves than in the bark. From the XANES measurements (Table 2), it is possible to observe that about $34 \%$ of the sulfur in the leaves is present in the form of sulfates, whereas in the bark only around $4 \%$ of the sulfur is present in a sulfate form.

Since sulfur is usually taken from the soil in a sulfate form, our results suggest that in Andira suraminensis sulfur is mainly transported to the leaves, either for storage or for further transformation into reduced organic forms.

\section{Conclusions}

The elementary composition of the bark and leaf of Andira surinamensis, a plant native to the Amazon rainforest, has been determined using two multi-element techniques: X-ray fluorescence (with a conventional source and synchrotron radiation) and Rutherford backscattering

Table 4. Results of linear combination fitting (LCF) of Andira surinamensis bark and leaf calculated by ATHENA

\begin{tabular}{|c|c|c|c|c|}
\hline Compound & Functional group & Oxidation state ${ }^{23,30,31}$ & Bark / \% & Leaf / \% \\
\hline Oxidized glutathione & disulfide & 0.2 & $34.8 \pm 1.3$ & $16.4 \pm 1.5$ \\
\hline Reduced glutathione & thiol & 0.4 & - & $27.8 \pm 1.5$ \\
\hline Methionine & thioether & 0.5 & $21.8 \pm 1.1$ & - \\
\hline DMSO & sulfoxide & 2 & $31.4 \pm 0.5$ & $15.9 \pm 0.4$ \\
\hline L-Methionine sulfone & sulfone & 4 & $3.1 \pm 0.5$ & - \\
\hline Cysteic acid & sulfonic acid & 5 & $4.5 \pm 0.5$ & $5.8 \pm 0.3$ \\
\hline Inorganic sulfate & inorganic sulfate & 6 & $4.3 \pm 0.3$ & $34.1 \pm 0.3$ \\
\hline
\end{tabular}

DMSO: dimethyl sulfoxide. 
spectrometry. In both techniques, quantification of the results was based on an entirely standard-less procedure. Calcium, barium, and strontium are present in higher concentrations in the bark, while magnesium, aluminum, silicon, phosphorus, sulfur, chlorine, and potassium were observed in higher concentrations in the leaf. Considering the very low concentration elements (less than $50 \mu \mathrm{g} \mathrm{g}^{-1}$ ) we have observed that zinc is present in lower concentration in the leaf sample, while manganese and copper were only observed in the leaf. The presence of barium and strontium, confirmed by $\mathrm{X}$-ray fluorescence and Rutherford backscattering spectrometry, calls the attention to the possible role played by Andira surinamensis in the accumulation of alkaline earths.

Chemical speciation of sulfur was performed using the XANES technique. In the bark and leaves of Andira suraminensis, sulfur is present in a diversity of oxidation states $(0.2,0.4,0.5,2,4,5$ and 6$)$. Within our limit of detection, elemental sulfur was not observed. Most of the sulfur observed in the leaves was found as an inorganic sulfate $(34.1 \%)$. Our results suggest that in Andira suraminensis sulfur, which is usually taken from the soil as a sulfate, is mainly transported to the leaves, either for storage or for further transformation into reduced organic forms.

\section{Supplementary Information}

Supplementary data are available free of charge at http://jbcs.sbq.org.br as PDF file.

\section{Acknowledgments}

The authors would like to acknowledge the SXS beamline staff for technical support. They also thank Prof José Fuentes and Pharm. Pamela Carignani for their valuable contributions. This study was financed in part by the Coordenação de Aperfeiçoamento de Pessoal de Nível Superior (CAPES), Brazil, finance code 001. The authors would like to acknowledge CNPq, FAPERJ, FAPERGS, and LNLS for the financial support.

\section{References}

1. Chuparina, E. V.; Smagunova, A. N.; Eliseeva, L. A.; J. Anal. Chem. 2015, 70, 949.

2. Marguí, E.; Queralt, I.; Hidalgo, M.; TrAc, Trends Anal. Chem. 2009, 28, 362.

3. Baxter, I. R.; Vitek, O.; Lahner, B.; Muthukumar, B.; Borghi, M.; Morrissey, J.; Guerinot, M. L.; Salt, D. E.; Proc. Natl. Acad. Sci. U. S. A. 2008, 105, 12081.
4. van Maarschalkerweerd, M.; Husted, S.; Front. Plant Sci. 2015 , 6, 169.

5. Baxter, I.; Dilkes, B. P.; Science 2012, 366, 1661.

6. Punshon, T.; Guerinot, M. L.; Lanzirotti, A.; Ann. Bot. 2009, 103, 665 .

7. Chao, D.-Y.; Baraniecka, P.; Danku, J.; Koprivova, A.; Lahner, B.; Luo, H.; Yakubova, E.; Dilkes, B.; Kopriva, S.; Salt, D. E.; Plant Physiol. 2014, 166, 1593.

8. Williams, J. S.; Cooper, R. M.; Physiol. Mol. Plant Pathol. 2003, 63, 3.

9. Cooper, R. M.; Williams, J. S.; J. Exp. Bot. 2004, 55, 1947.

10. Andersen, L. K.; Morgan, T.; Boulamanti, A.; Álvarez, P.; Vassilev, S.; Baxter, D.; Energy Fuels 2013, 27, 7439.

11. Margui, E.; Hidalgo, M.; Queralt, I.; Spectrochim. Acta, Part B 2005, 60, 1363.

12. Wu, B.; Becker, J. S.; Metallomics 2012, 4, 403.

13. Bruker; S8 Tiger Operator's Manual; Bruker: Karlsruhe, 2009.

14. Jenkins, R.; X-Ray Fluorescence Spectrometry, $2^{\text {nd }}$ ed.; John Wiley \& Sons: New York, 1999.

15. Haschke, M.; Laboratory Micro-X-Ray Fluorescence Spectroscopy; Springer: Cham, 2014.

16. Andrey, D.; Dufrier, J. P.; Perring, L.; Spectrochim. Acta, Part B 2018, 148, 137.

17. National Institute of Standards and Technology (NIST); Standard Reference Material 1570a - Trace Elements in Spinach Leaves; NIST: Gaithersburg, 2014.

18. Abbate, M.; Vicentin, F. C.; Compagnon-Cailhol, V.; Rocha, M. C.; Tolentino, H.; J. Synchrotron Radiat. 1999, 6, 964.

19. Chu, W. K.; Mayer, J. W.; Nicolet, M. A.; Backscattering Spectrometry; Academic Press: New York, 1963.

20. Foti, G.; Mayer, J. W.; Rimini, E.; Ion Beam Handbook for Materials Analysis; Academic Press: New York, 1977, ch. 2.

21. Lanford, W. A.; Parenti, M.; Nordell, B. J.; Paquette, M. M.; Caruso, A. N.; Mäntymäki, M.; Hämäläinen, J.; Ritala, M.; Klepper, K. B.; Miikkulainen, V.; Nilsen, O.; Tenhaeff, W.; Dudney, N.; Koh, D.; Banerjee, S. K.; Mays, E.; Bielefeld, J.; King, S. W.; Nucl. Instrum. Methods Phys. Res., Sect. B 2016, $371,211$.

22. George, G. N.; Gorbaty, M. L.; J. Am. Chem. Soc. 1989, 111, 3182.

23. Waldo, G. S.; Carlson, R. M. K.; Moldowan, J. M.; Peters, K. E.; Penner-Hahn, J. E.; Geochim. Cosmochim. Acta 1991, 55, 801.

24. Huffman, G. P.; Mitra, S.; Huggins, F. E.; Shah, N.; Vaidya, S.; Lu, F.; Energy Fuels 1991, 5, 574.

25. Waldo, G. S.; Mullins, O. C.; Penner-Hahn, J. E.; Cramer, S. P.; Fuel 1992, 71, 53.

26. Huffman, G. P.; Shah, N.; Huggins, F. E.; Stock, L. M.; Chatterjee, K.; Kilbane, J. J.; Chou, M.-I. M.; Buchanan, D. H.; Fuel 1995, 74, 549. 
27. Vairavamurthy, M. A.; Maletic, D.; Wang, S.; Manowitz, B.; Eglinton, T.; Lyons, T.; Energy Fuels 1997, 11, 546.

28. Pickering, I. J.; Prince, R. C.; Divers, T.; George, G. N.; FEBS Lett. 1998, 441, 11.

29. Rompel, A.; Cinco, R. M.; Latimer, M. J.; McDermott, A. E.; Guiles, R. D.; Quintanilha, A.; Krauss, R. M.; Sauer, K.; Yachandra, V. K.; Klein, M. P.; Proc. Natl. Acad. Sci. U. S. A. 1998, 95, 6122.

30. Vairavamurthy, M. A.; Spectrochim. Acta, Part A 1998, 54, 2009.

31. Xia, K.; Weesner, F.; Blam, W. F.; Bloom, P. R.; Skyllberg, U. L.; Helmke, P. A.; Soil Sci. Soc. Am. J. 1998, 62, 1240.

32. Frank, P.; Caruso, F.; Caponetti, E.; Anal. Chem. 2012, 84, 4419.

33. Riquelme, F.; Northrup, P.; Ruvalcaba-Sil, J. L.; Stojanoff, V.; Siddons, D. P.; Alvarado-Ortega, J.; Appl. Phys. A: Mater. Sci. Process. 2014, 116, 97.

34. Wasserman, S. R.; Allen, P. G.; Shuh, D. K.; Bucher, J. J.; Edelstein, N. M.; J. Synchrotron Radiat. 1999, 6, 284.

35. Beauchemin, S.; Hesterberg, D.; Beauchemin, M.; Soil Sci. Soc. Am. J. 2002, 66, 83.

36. Prange, A.; Dahl, C.; Truper, H. G.; Behnke, M.; Hahn, J.; Modrow, H.; Hormes, J.; Eur. Phys. J. D 2002, 20, 589.

37. Solomon, D.; Lehmann, J.; Martinez, C. E.; Soil Sci. Soc. Am. J. 2003, 67, 1721.

38. Jalilehvand, F.; Chem. Soc. Rev. 2006, 35, 1256.

39. Zhao, F. J.; Lehmann, J.; Solomon, D.; Fox, M. A.; McGrath, S. P.; Soil Biol. Biochem. 2006, 38, 1000.

40. Almkvist, G.; Boye, K.; Persson, I.; J. Synchrotron Radiat. 2010, 17, 683 .

41. Prietzel, J.; Botzaki, A.; Tyufekchieva, N.; Brettholle, M.; Thieme, J.; Klysubun, W.; Environ. Sci. Technol. 2011, 45, 2878.

42. Veronesi, G.; Koudouna, E.; Cotte, M.; Martin, F. L.; Quantock, A. J.; Anal. Bioanal. Chem. 2013, 405, 6613.

43. Frank, P.; Hedman, B.; Hodgson, K. O.; Inorg. Chem. 1999, 38, 260.

44. Thomson, A.; Atwood, D.; Gullikson, E.; Howells, M.; Kim, K.-J.; Kirz, J.; Kortright, J.; Lindau, I.; Liu, Y.; Pianetta, P.; Robinson, A.; Scofield, J.; Underwood, J.; Williams, G.; $X$-Ray Data Booklet; Lawrence Berkeley National Laboratory, University of California: Berkeley, 2009.

45. https://www.esrf.eu/UsersAndScience/Experiments/XNP/ID21, accessed in April 2019.
46. Simões, G.; Rodrigues, F. N.; Bernini, R. B.; Castro, C. S. C.; Souza, G. G. B.; J. Electron Spectrosc. Relat. Phenom. 2014, 193, 21.

47. Ravel, B.; Newville, M.; J. Synchrotron Radiat. 2005, $12,537$.

48. Coscione, A. R.; Berton, R. S.; Sci. Agric. 2009, 66, 59.

49. Myrvang, M. B.; Gjengedal, E.; Heim, M.; Krogstad, T.; Almås, Å. R.; Appl. Geochem. 2016, 75, 1.

50. Abreu, C. A.; Cantoni, M.; Coscione, A. R.; Paz-Ferreiro, J.; Appl. Environ. Soil Sci. 2012, 2012, 476821.

51. Chuparina, E. V.; Aisueva, T. S.; Environ. Chem. Lett. 2011, 9 , 19.

52. Tian, S.; Lu, L.; Yang, X.; Webb, S. M.; Du, Y.; Brown, P. H.; Environ. Sci. Technol. 2010, 44, 5920.

53. Biondi, C. M.; Nascimento, C. W. A.; Neta, A. B. F.; Rev. Bras. Cienc. Solo 2011, 35, 1819.

54. Pérez, D. V.; Saldanha, M. F. C.; Meneguelli, N. A.; Moreira, J. C.; Vaitsman, D. S.; Geoquímica de Alguns Solos Brasileiros; Embrapa-Centro Nacional de Pesquisa de Solos: Rio de Janeiro, 1997.

55. He, H.; Bleby, T. M.; Veneklaas, E. J.; Lambers, H.; Kuo, J.; PLoS One 2012, 7, e41563.

56. Bewer, B.; Nucl. Instrum. Methods Phys. Res., Sect. B 2015, $347,1$.

57. Sutton, S. R.; Bertsch, P. M.; Newville, M.; Rivers, M.; Lanzirotti, A.; Eng, P.; Rev. Mineral. Geochem. 2002, 49, 429.

58. Joint Committee for Guides in Metrology (JCGM); Evaluation of Measurement Data - Guide to the Expression of Uncertainty in Measurement (GUM), 1 1st ed.; JCGM: Sèvres, 2008.

59. https://www.nist.gov/pml/xcom-photon-cross-sectionsdatabase, accessed in April 2019.

60. Stedile, F. C.; Santos, J. H. Z.; Nucl. Instrum. Methods Phys. Res., Sect. B 1998, 136-138, 1259.

61. Bichinho, K. M.; Pires, G. P.; Stedile, F. C.; Santos, J. H. Z.; Spectrochim. Acta, Part B 2002, 57, 1877.

62. Zeng, J.; Zhang, G.; Bao, L.; Long, S.; Tan, M.; Li, Y.; Ma, C.; Zhao, Y.; J. Environ. Sci. 2013, 25, 605.

63. Zhang, L.-L.; Wang, C.-L.; Zhao, Y.-S.; Yang, G.-H.; Su, M.; Yang, C.-H.; J. Fuel Chem. Technol. 2013, 41, 1328.

Submitted: January 29, 2019

Published online: May 17, 2019 